\title{
Effect of Moment of Inertia of Attached Mass on Natural Frequencies of Cantilevered Symmetrically Laminated Plates
}

\author{
Kenji Hosokawa ${ }^{a, *}$ \\ a'Department of Mechanical Engineering, Chubu University. Email: hosokawa@ isc.chubu.ac.jp
}

\begin{abstract}
Since composite materials such as laminated composite plates have high specific strength and high structural efficiency, they have been used in many structural applications. It is therefore very important to make clear the vibration characteristics of the laminated plates for the design and the structural analysis. Especially, the vibration characteristics of the laminated plates with attached mass are essential. However, we cannot find the theoretical or experimental approaches for the free vibration of laminated plates with attached mass. In the present study, the experimental and numerical approaches are applied to the free vibration of cantilevered symmetrically laminated plates with attached mass. First, by applying the experimental modal analysis technique to the cantilevered symmetrically laminated plates with attached mass, the natural frequencies and mode shapes of the plates are obtained. Next, the natural frequencies and mode shapes of the cantilevered symmetrically laminated plates with attached mass are calculated by Finite Element Method (FEM). Finally, from the experimental and numerical results, the effect of the moment of inertia of the attached mass to the natural frequencies and mode shapes of the cantilevered symmetrically laminated plates are clarified.
\end{abstract}

Keywords: Composite material; experimental modal analysis; FEM; free vibration; vibration of continuous system

\section{Introduction}

Since aerospace structures require the high specific strength and high specific modulus, many composite materials such as carbon fiber reinforced plastics (CFRP) have been used. Also, in many engineering applications, the substructures may be added to the laminated composite plates. For example, the problem of plates with attached masses relates to the design of electronic systems. These attachments affect the vibration characteristics of the laminated composite plates.

Many studies on the free vibrations of a thin isotropic plate with attached mass have been reported in the literature [1-6]. However, studies on the free vibrations of laminated plate with attached mass are limited. Using the Hamilton's principle by means of a double Fourier series, the free vibration of a simply supported laminated composite plate with distributed patch mass is solved by Alibeigloo et al. [7]. Malekzadeh et al. analyzed the free vibration of the rectangular composite plate with distributed attached mass by using the standard Galerkin procedure [8]. As mentioned above, one can find a few published researches on a

\footnotetext{
${ }^{*}$ Corresponding author. Tel.: +81-568-51-9345

1200 Matsumoto-cho

Kasugai, Aichi, Japan, 487-8501
}

numerical analysis of the free vibration of the laminated composite plate with attached mass. However, only few reports can be found on an experimental analysis of the free vibration of the laminated composite plate with attached mass.

In the present study, the experimental and numerical approaches are applied to the cantilevered symmetrically laminated plates with attached mass. First, by applying the experimental modal analysis technique to the cantilevered symmetrically laminated plates with attached mass, the natural frequencies and mode shapes of the plates are obtained. Next, the natural frequencies and mode shapes of the cantilevered symmetrically laminated plates with attached mass are calculated by Finite Element Method (FEM). Finally, from the experimental and numerical results, the effect of the moment of inertia of attached mass to the natural frequencies and mode shapes of the cantilevered symmetrically laminated plates are studied

\section{CFRP Laminated Plates}

The symmetrically laminated square and trapezoidal plates were used. Each layer material, that is lamina, is reinforced by carbon fibers. This fiber's tensile elastic modulus is $230 \mathrm{GPa}$. The matrix is an epoxy resin $\left(130^{\circ} \mathrm{C}\right.$ cure). The fiber volume fraction is $55 \%$. The laminae of the 


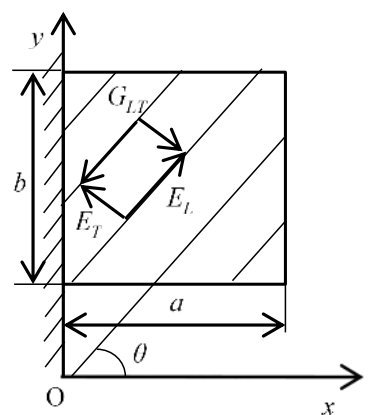

(a) Square plate

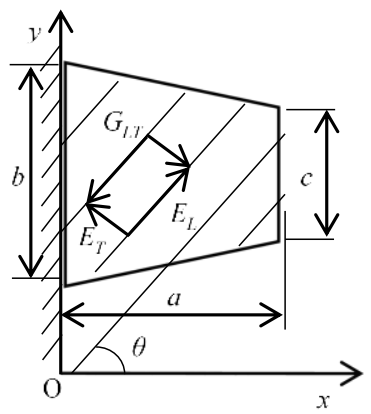

(b) Trapezoidal plate
Figure 1. Lamina of cantilevered plate

Table 1. Material properties of lamina

\begin{tabular}{cccc}
\hline$E_{L}(\mathrm{GPa})$ & $E_{T}(\mathrm{GPa})$ & $G_{L T}(\mathrm{GPa})$ & $v_{L T}$ \\
\hline 97.6 & 6.26 & 5.18 & 0.33 \\
\hline
\end{tabular}

square and trapezoidal plates are made of the same layer material and the both plates were made under the same curing condition. As shown in Fig. 1, the plate configuration of the square plate is as follows: $a=0.2 \mathrm{~m}, b=0.2 \mathrm{~m}$. The stacking sequence of the square plate is $[-\theta /+\theta /+\theta /-\theta]$, fiber orientation angle $\theta=60^{\circ}$ and the plate thickness $h$ is $1.6 \times 10^{-3} \mathrm{~m}$. And, the plate configuration of trapezoidal plate is as follows: $a=0.2 \mathrm{~m}, b=0.2 \mathrm{~m}, c=0.1 \mathrm{~m}$. The stacking sequence of the trapezoidal plate is $[-\theta /+\theta /+\theta /-\theta]$, fiber orientation angle $\theta=30^{\circ}$ and the plate thickness $h$ is $1.6 \times 10^{-3} \mathrm{~m}$. The density of the both laminated plates is 1535 $\mathrm{kg} / \mathrm{m}^{3}$. The measured material properties of the lamina are listed in Table 1. Table 1 shows the moduli of elasticity $E_{L}$, $E_{T}$ in the direction of the parallel and normal to the fiber, respectively, shear modulus $G_{L T}$, and Poisson's ratios $v_{L T}$ of each layer (See Fig. 1).

\section{Attached Mass}

In this study, three different shapes of attached mass were used. The shape of the attached mass is shown in Fig. 2. The dimensions of masses are presented by Table 2 . The bottom part is the hexagon nut (M5; JIS). The mass of these attached masses is the same by $21 \mathrm{~g}$. Also, the moment of inertia of these masses are shown in Table 3. The attached mass was bonded to the plate by epoxy based adhesive.

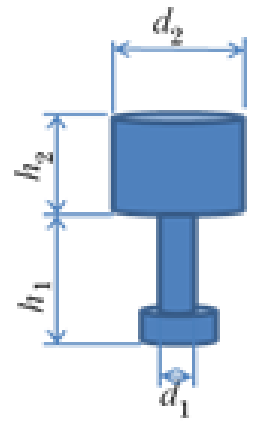

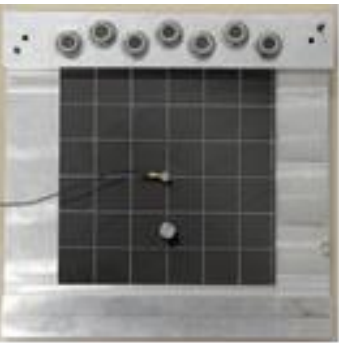

(a) square plate

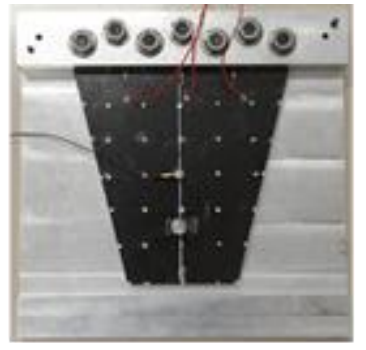

(b) trapezoidal plate
Figure 3. Clamping fixture of cantilevered plate

Figure 2. Shape of attached mass 


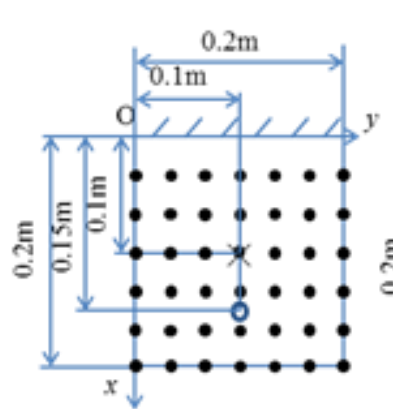

(a) square plate

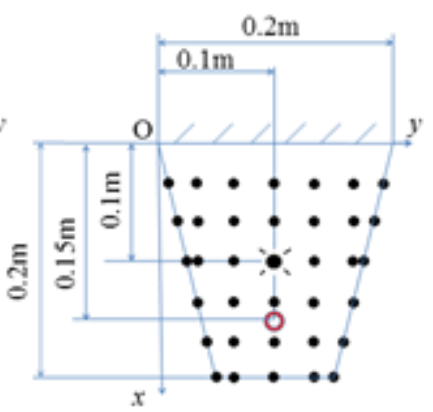

(b) trapezoidal plate
Figure 4. Reference points of laminated plate

Table 4. Material properties of lamina

\begin{tabular}{ccccc}
\hline$E_{V}(G P a)$ & $E_{T V}(G P a)$ & $G_{V L}(G P a)$ & $v_{T V}$ & $v_{V L}$ \\
\hline 6.26 & 2.41 & 5.18 & 0.33 & 0.02 \\
\hline
\end{tabular}

\subsection{Finite Element Method (FEM)}

The computations were carried out using the FEM eigenvalue program with solid elements. Each layer is divided into 3600 elements. Therefore, each plate is divided into 14400 elements. In the numerical calculations, the mass of the accelerometer was considered. Also, the material properties shown in Table 1 were used. Furthermore, to apply the FEM (LS-DYNA), the material properties in the plate thickness direction ( $V$ axis) are need. Therefore, the other parameters shown in Table 4 were estimated in reference to literature [9].

\subsection{Comparison of experimental and numerical results}

Figure 5 shows the natural frequencies and mode shapes of the cantilevered laminated square plate without attached mass. And, Figure 6 shows the natural frequencies and mode shapes of the cantilevered laminated trapezoidal plate without attached mass. In these figures, the upper edge of the plate is a clamped edge, the notation $\times$ represents the location of the attached accelerometer. From these figures, one can see that the difference between experimental and

\begin{tabular}{c|cccccc|c}
\hline \hline Modal order & 1st & 2nd & 3rd & 4th & 5th & 6th \\
\hline $\begin{array}{c}\text { Numerical } \\
\text { mode shape }\end{array}$ & $\times$ & $\times$ & $\times$ & $\times$ & $\times$ & $\times$ \\
\hline $\begin{array}{c}\text { Numerical } \\
\text { natural } \\
\text { frequency (Hz) }\end{array}$ & 17.72 & 69.95 & 109.0 & 206.7 & 272.7 & 348.5 \\
\hline $\begin{array}{c}\text { Experimental } \\
\text { mode shape }\end{array}$ & $\times$ & $\times$ & $\times$ & $\times$ & $\times$ & $\times$ \\
\hline $\begin{array}{c}\text { Experimental } \\
\text { natural } \\
\text { frequency (Hz) }\end{array}$ & 17.15 & 71.53 & 105.4 & 213.5 & 272.8 & 351.8 \\
\hline \begin{tabular}{c} 
Error(\%) \\
\hline
\end{tabular} & 3.3 & -2.2 & 3.4 & -3.2 & -0.04 & -0.94 \\
\hline
\end{tabular}

Figure 5. Experimental and analytical results of FRP laminated square plate without attached mass

\begin{tabular}{|c|c|c|c|c|c|c|}
\hline Modal order & 1 st & 2 nd & 3 rd & 4 th & 5 th & 6 th \\
\hline $\begin{array}{l}\text { Numerical } \\
\text { mode shape }\end{array}$ & & & & & & \\
\hline $\begin{array}{c}\text { Numerical } \\
\text { natural } \\
\text { frequency }(\mathrm{Hz}) \\
\end{array}$ & 43.35 & 134.6 & 241.5 & 337.2 & 423.0 & 589.6 \\
\hline $\begin{array}{l}\text { Experimental } \\
\text { mode shape }\end{array}$ & & & & & & \\
\hline $\begin{array}{c}\text { Experimental } \\
\text { natural } \\
\text { frequency }(\mathrm{Hz})\end{array}$ & 43.42 & 136.5 & 241.3 & 347.9 & 427.8 & 611.7 \\
\hline Error(\%) & -0.16 & -1.4 & 0.08 & -3.1 & -1.1 & -3.6 \\
\hline
\end{tabular}

Figure 6. Experimental and analytical results of FRP laminated trapezoidal plate without attached mass

numerical natural frequencies is about $3.6 \%$ at the most. Also, it follows that one can find good agreement between experimental and numerical mode shapes.

\section{Effect of Moment of Inertia of Attached Mass}

Figures 7 to Figure 9 show the natural frequencies and mode shapes of the laminated square plate with attached mass. Also, Figure 10 to Figure 12 show the natural frequencies and mode shapes of the laminated trapezoidal plate with attached mass. In these figures, the upper edge of the plate is a clamped edge, the notation $\bullet$ represents the location of attached mass, and $\times$ represents the location of the attached accelerometer. From the numerical and experimental results, the similar results were obtained. The natural frequency of the plates with attached mass is smaller than that of the plates without attached mass. With the increase of the moment of inertia of the attached mass, the natural frequency of the plate is decreasing. Also, the lower mode shapes do not change with the increase of the moment of inertia of the attached mass.

\begin{tabular}{|c|c|c|c|c|c|c|}
\hline Modal order & 1st & 2nd & 3rd & 4th & 5 th & 6th \\
\hline $\begin{array}{l}\text { Numerical } \\
\text { mode shape }\end{array}$ & - & • & - & & & - \\
\hline $\begin{array}{c}\text { Numerical } \\
\text { natural } \\
\text { frequency }(\mathrm{Hz})\end{array}$ & 15.03 & 68.55 & 104.7 & 190.8 & 268.4 & 299.7 \\
\hline $\begin{array}{l}\text { Experimental } \\
\text { mode shape }\end{array}$ & $\begin{array}{l}x \\
\bullet\end{array}$ & $x$ & & & & \\
\hline $\begin{array}{c}\text { Experimental } \\
\text { natural } \\
\text { frequency }(\mathrm{Hz})\end{array}$ & 14.85 & 71.30 & 102.1 & 198.2 & 264.0 & 299.3 \\
\hline Error(\%) & 1.2 & -3.9 & 2.5 & -3.7 & 1.7 & 0.13 \\
\hline
\end{tabular}

Figure 7. Experimental and analytical results of FRP laminated square plate with attached mass $(\mathrm{K})$ 


\begin{tabular}{c|ccccccc}
\hline \hline Modal order & 1st & 2nd & 3rd & 4th & 5th & 6th \\
\hline $\begin{array}{c}\text { Numerical } \\
\text { mode shape }\end{array}$ & $:$ & $\vdots$ & $\vdots$ & $\vdots$ & $:$ & $:$ \\
\hline $\begin{array}{c}\text { Numerical } \\
\text { natural } \\
\text { frequency (Hz) }\end{array}$ & 15.00 & 68.00 & 102.5 & 190.8 & 265.1 & 293.4 \\
\hline $\begin{array}{c}\text { Experimental } \\
\text { mode shape }\end{array}$ & $\times$ & $\times$ & $\times$ & $\times$ & $\times$ & $\times$ \\
\hline $\begin{array}{c}\text { Experimental } \\
\text { natural } \\
\text { frequency (Hz) }\end{array}$ & 14.83 & 70.19 & 99.89 & 198.0 & 262.4 & 293.9 \\
\hline \begin{tabular}{c} 
Error(\%) \\
\hline
\end{tabular} & 1.1 & -3.1 & 2.6 & -3.6 & 1.0 & -0.17 \\
\hline
\end{tabular}

Figure 8. Experimental and analytical results of FRP laminated square plate with attached mass (L)

\begin{tabular}{|c|c|c|c|c|c|c|}
\hline Modal order & $1 \mathrm{st}$ & 2nd & $3 \mathrm{rd}$ & 4th & 5 th & 6th \\
\hline $\begin{array}{l}\text { Numerical } \\
\text { mode shape }\end{array}$ & - & • & . & & $\cdot$ & \\
\hline $\begin{array}{c}\text { Numerical } \\
\text { natural } \\
\text { frequency }(\mathrm{Hz})\end{array}$ & 14.98 & 67.37 & 100.1 & 190.8 & 257.1 & 285.0 \\
\hline $\begin{array}{l}\text { Experimental } \\
\text { mode shape }\end{array}$ & - & & & & & \\
\hline $\begin{array}{c}\text { Experimental } \\
\text { natural } \\
\text { frequency }(\mathrm{Hz})\end{array}$ & 14.70 & 69.35 & 97.12 & 197.9 & 243.3 & 284.1 \\
\hline Error(\%) & 1.9 & -2.9 & 3.1 & -3.6 & 5.7 & 0.32 \\
\hline
\end{tabular}

Figure 9. Experimental and analytical results of FRP laminated square plate with attached mass $(\mathrm{M})$

\begin{tabular}{|c|c|c|c|c|c|c|}
\hline Modal order & 1 st & 2nd & $3 \mathrm{rd}$ & 4 th & 5 th & 6 th \\
\hline $\begin{array}{l}\text { Numerical } \\
\text { mode shape }\end{array}$ & - & & & & & \\
\hline $\begin{array}{c}\text { Numerical } \\
\text { natural } \\
\text { frequency }(\mathrm{Hz})\end{array}$ & 33.87 & 125.0 & 226.6 & 296.6 & 382.3 & 454.9 \\
\hline $\begin{array}{l}\text { Experimental } \\
\text { mode shape }\end{array}$ & - & & & & & \\
\hline $\begin{array}{c}\text { Experimental } \\
\text { natural } \\
\text { frequency }(\mathrm{Hz})\end{array}$ & 34.11 & 126.8 & 224.9 & 305.4 & 392.0 & 450.5 \\
\hline Error(\%) & -0.70 & -1.4 & 0.76 & -2.9 & -2.5 & 1.0 \\
\hline
\end{tabular}

Figure 10. Experimental and analytical results of FRP laminated trapezoidal plate with attached mass $(\mathrm{K})$

\begin{tabular}{|c|c|c|c|c|c|c|}
\hline Modal order & $1 \mathrm{st}$ & 2nd & $3 \mathrm{rd}$ & 4th & 5 th & 6 th \\
\hline $\begin{array}{l}\text { Numerical } \\
\text { mode shape }\end{array}$ & $\bullet$ & & & & ${ }^{\circ}$ & \\
\hline $\begin{array}{c}\text { Numerical } \\
\text { natural } \\
\text { frequency }(\mathrm{Hz})\end{array}$ & 34.19 & 119.8 & 221.9 & 292.4 & 347.1 & 436.1 \\
\hline $\begin{array}{l}\text { Experimental } \\
\text { mode shape }\end{array}$ & & & & & & \\
\hline $\begin{array}{c}\text { Experimental } \\
\text { natural } \\
\text { frequency }(\mathrm{Hz})\end{array}$ & 33.91 & 121.6 & 216.4 & 297.9 & 343.8 & 424.0 \\
\hline Error(\%) & 0.83 & -1.5 & 2.5 & -1.8 & 1.0 & 2.9 \\
\hline
\end{tabular}

Figure 11. Experimental and analytical results of FRP laminated trapezoidal plate with attached mass $(\mathrm{L})$

\begin{tabular}{|c|c|c|c|c|c|c|}
\hline Modal order & 1 st & 2nd & $3 \mathrm{rd}$ & 4 th & 5 th & 6th \\
\hline $\begin{array}{l}\text { Numerical } \\
\text { mode shape }\end{array}$ & - & & & & & \\
\hline $\begin{array}{c}\text { Numerical } \\
\text { natural } \\
\text { frequency }(\mathrm{Hz})\end{array}$ & 33.55 & 114.5 & 209.5 & 288.7 & 316.0 & 420.6 \\
\hline $\begin{array}{l}\text { Experimental } \\
\text { mode shape }\end{array}$ & 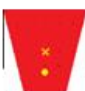 & & & & & \\
\hline $\begin{array}{c}\text { Experimental } \\
\text { natural } \\
\text { frequency }(\mathrm{Hz})\end{array}$ & 33.82 & 116.9 & 207.4 & 290.8 & 319.7 & 408.4 \\
\hline Error(\%) & -0.80 & -2.1 & 1.0 & -0.72 & -1.2 & 3.0 \\
\hline
\end{tabular}

Figure 12. Experimental and analytical results of FRP laminated trapezoidal plate with attached mass $(\mathrm{M})$

\section{Conclusions}

The experimental and numerical approaches were applied to the free vibration of cantilevered symmetrically laminated plates with and without the attached mass. First, by applying the experimental modal analysis technique to the cantilevered symmetrically laminated plates with and without the attached mass, the natural frequencies and mode shapes of the plates were obtained. Next, the natural frequencies and mode shapes of the cantilevered symmetrically laminated plates with and without the attached mass were calculated by Finite Element Method (FEM).

From the all experimental and numerical results, one can see that the difference between experimental and numerical natural frequencies is about $5.7 \%$ at the most. Also, it follows that one can find good agreement between all experimental and numerical mode shapes. Accordingly, one can see good agreement between experimental and numerical results. 
From the experimental and numerical results, it follows that: (1) the natural frequency of the plates with attached mass is smaller than that of the plates without attached mass, (2) the fundamental natural frequency of the plates is hardly influenced by the difference in the moment of inertia of the attached mass, (3) with the increase of the moment of inertia of the attached mass, the natural frequency of the plate is decreasing, (4) the higher mode shapes of the plates change with the increase of the moment of inertia of the attached mass. Therefore, not considering the shape of attached mass and considering the attached mass as the concentrated load, it is a problem to analyze the free vibration of the laminated plate with attached mass.

\section{Acknowledgements}

The author would like to convey a great appreciation to Mr. Nakagawa and Mr. Nakamura for assisting this research.

\section{References}

[1] R. E. Rossi and P. A. A. Laura, Symmetric and Antisymmetric Normal Modes of a Cantilever Rectangular Plate: Effect of Poisson's Ratio and a Concentrated Mass, Journal of Sound and Vibration, Volume 195(1), 1996, p. 142-148.
[2] K. H. Low, G. B. Chai, T. M. Lim, and S. C. Sue, Comparison of experimental and theoretical frequencies foe rectangular plates with various boundary conditions and added masses, International Journal of Mechanical Sciences Volume 40(11), 1998, pp.1119-1131.

[3] O. Kompaz and S. Telli, Free Vibration of a Rectangular Plate Carrying Distributed Mass, Journal of Sound Vibration, Volume 251(1), 2002, pp.39-57.

[4] W. O. Wong, The Effect of Distributed Mass Loading on PlateVibration Behavior, Journal of Sound and Vibration, Volume 252(3), 2002, pp.577-583.

[5] M. Amabili, M. Pellegrini, F. Righi, and F. Vinci, Effect of concentrated masses with rotary inertia on vibrations of rectangular plate, Journal of Sound and Vibration, Volume 295(1), 2006, pp.1-12.

[6] S. D. Yu, Free and forced flexural vibration analysis of cantilever plates with attached point mass, Journal of Sound and Vibration, Volume 321(1-2), 2009, pp.270-285.

[7] A. Alibeigloo, M. Shakeri and M. R. Kari, Free Vibration Analysis of Antisymmetric Laminated Rectangular Plates with Distributed Patch Mass Using Third-order Shear Deformation Theory, Ocean Engineering, Volume 35(2), 2007, pp.183-190.

[8] K. Malekzadeh, S. Tafazoli, and S.M.R. Khalili, Free Vibrations of Thick Rectangular Composite Plate with Uniformly Distributed Attached Mass Including Stiffness Effect, Journal of Composite Materials, Volume 44(24), 2010, pp.2897-2918.

[9] Y. Narita, Y. Ohta, and S. Morika, The Three Dimensional Vibration Analysis of Symmetrically Laminated, Cross-ply Thick Rectangular Plates, Proceedings of Japan-U.S. CCM-VII, Kyoto, 1995, pp.617623. 